\title{
Functionality of hospital information systems: results from a survey of quality directors at Turkish hospitals
}

\author{
Mehmet Saluvan $^{1 *}$ D and Al Ozonoff ${ }^{1,2}$
}

\begin{abstract}
Background: We aimed to determine availability of core Hospital Information Systems (HIS) functions implemented in Turkish hospitals and the perceived importance of these functions on quality and patient safety.

Methods: We surveyed quality directors (QDs) at civilian hospitals in the nation of Turkey. Data were collected via web survey using an instrument with 50 items describing core functionality of HIS. We calculated mean availability of each function, mean and median values of perceived impact on quality, and we investigated the relationship between availability and perceived importance.

Results: We received responses from 31\% of eligible institutions, representing all major geographic regions of Turkey. Mean availability of 50 HIS functions was $65.6 \%$, ranging from $19.6 \%$ to $97.4 \%$. Mean importance score was 7.87 (on a 9-point scale) ranging from 7.13 to 8.41. Functions related to result management (89.3\%) and decision support systems (52.2\%) had the highest and lowest reported availability respectively. Availability and perceived importance were moderately correlated $(r=0.52)$.

Conclusion: QDs report high importance of the HIS functions surveyed as they relate to quality and patient safety. Availability and perceived importance of HIS functions are generally correlated, with some interesting exceptions. These findings may inform future investments and guide policy changes within the Turkish healthcare system. Financial incentives, regulations around certified HIS, revisions to accreditation manuals, and training interventions are all policies which will help integrate HIS functions to support quality and patient safety in Turkish hospitals.
\end{abstract}

Keywords: Hospital information systems, Electronic health records, Healthcare quality, Patient safety, Health information technology

\section{Background}

There have been steady efforts to improve quality in healthcare since the early 2000s, kickstarted by two reports released by the Institute of Medicine (IOM) [1]. The first report asserts that healthcare is not as safe as it should be and offers a substantial body of evidence pointing to medical errors as a leading cause of death and injury in the United States (U.S.). The second report focuses more broadly on how the healthcare delivery system can be redesigned to innovate and improve care [2]. Both reports suggest making effective use of

\footnotetext{
* Correspondence: Mehmet.Saluvan@childrens.harvard.edu ${ }^{1}$ Center for Applied Pediatric Quality Analytics, Boston Children's Hospital, 300 Longwood Avenue, Boston, MA 02115, USA

Full list of author information is available at the end of the article
}

information technologies as one of six necessary strategies for the redesign of healthcare systems $[2,3]$ and express concern over slow uptake of information technology in healthcare. Healthcare is an information-based science [4] and providers must have access to timely and accurate information to provide safe high-quality care [5]. Clearly, information management and health information technology (HIT) are fundamental to current and future healthcare delivery in the U.S., $[6,7]$ United Kingdom (U.K.), [8] and elsewhere [9-15].

Modern healthcare makes wide use of information technology $[16,17]$. Most stakeholders agree that information technology such as electronic health records (EHRs) and computerized provider order entry (CPOE) will be critical to transforming the healthcare industry 
[6]. According to the IOM, HIT must play a central role in the redesign of the healthcare system if a substantial improvement in quality is to be achieved over the coming decade. Given the complexity of modern medicine, it is inevitable that HIT will play an ever increasing role in improving healthcare quality [18]. The imperatives of improving documentation, reducing error, and empowering patients will continue to use of information technology in healthcare. There is plenty of evidence that clinical informatics applications can address these imperatives to enhance patient outcomes, reduced costs, and provide access to knowledge [19].

Otherwise, healthcare costs are rising and all parties involved-government, insurers, hospitals and patientsare concerned. Costs must be reduced, but without major compromise of quality $[20,21]$. The widespread adoption of HIT may reduce costs by way of improved efficiency and less duplication of effort in delivery of care services as well as a reduction in costly medical errors [22, 23]. Payment systems and provisions from payers have further incentivized the use of information systems in healthcare [24]. For example, the Centers for Medicare and Medicaid Services (CMS) provide up to $\$ 27 \mathrm{~B}$ of incentive payments over 10 years to hospitals and healthcare providers that demonstrate meaningful use of certified electronic health record (EHR) systems in the U.S. $[25,26]$. Simply put, "meaningful use" requires providers to demonstrate use of HIT to measure improvements in quality of care [27]. Similarly, England has invested at least $£ 12.8$ billion in a National Programme for Information Technology for the National Health Service in 2009 [15, 28].

Hospitals in particular are characterized by the high capacity of information and clinical data produced, and a new category of HIS now dominates in modern hospitals [16]. These systems aim to support high-quality, efficient, patient-centered care [29] with integrated support for the administrative and management tasks needed to support such care [30]. HIS systems have been shown to decrease the cost of quality care and the accessibility time to patient records [24]. The relevance of 'good' HIS for high-quality of care is obvious [29, 30]. Further advances of technology in healthcare include the use of information and communication technology (ICT) to support robust communications in an increasingly complex healthcare environment. ICT originally contributed to timely and efficient transmission of patient data, and its focus is now shifting to improve clinical data quality by using online clinical data acquisition and processing [31].

Implementation of HIS ${ }^{1}$ systems has increased globally over the past 5 years, and higher-income countries are further in adoption and utilization of HIS systems compared to lower-income countries [32]. There are many competing HIS vendors each with their own products and different capabilities [33]. Most hospitals in higher-income countries are using comprehensive HIS, [12, 34-36] while in other parts of the world hospital orders for medications, laboratory tests, and other services are still paper-based [37]. This situation leads to a natural question: which core functions of HIS should be adopted for maximum impact on quality and patient safety?

This question was partially addressed in a 2003 IOM report which identified eight categories of core functionalities: health information and data; results management; computerized physician order entry; decision support system; electronic communication and connectivity; patient support; administrative processes; and reporting and population health management [38].

There is general consensus that the use of HIT should lead to more efficient, safer, and higher quality care $[19,39,40]$. There are few studies and data available on HIS implementation in countries with less mature healthcare systems. We hope to close this gap and provide new data on HIT implementation in Turkey.

Therefore the aim of this study is to determine availability of core HIS functions implemented in Turkish hospitals and their perceived importance on quality and patient safety.

\section{Methods \\ Sampling frame}

All licensed civilian hospitals in the nation of Turkey were eligible for this survey. Invitations to respond were sent to the Quality Director of each hospital from a listing of contact information maintained by the Turkish Ministry of Health $(\mathrm{MoH})$. Military hospitals are not governed by the $\mathrm{MoH}$ and were excluded. In Turkish hospitals, QDs are responsible for planning and implementing quality and patient safety standards. Responsibilities of the QDs include: training and education of hospital staff; support and oversight of departmental quality committees; and coordination of internally and externally conducted audits [41]. We surveyed QDs since they are typically among the most knowledgeable staff about quality and patient safety aspects of hospital operations [42] (including use of HIS).

\section{Survey instrument}

We developed a survey instrument to collect data and perceptions on core functions of HIS implementation in Turkey. In order to develop the survey items, we began with national and international hospital quality standards maintained by the $\mathrm{MoH}$ and Joint Commission International. We reviewed features of HIS with supporting evidence to facilitate hospitals meeting these quality standards. We supplemented this initial list of 
items with information from our review of the literature $[38,39,41,43,44]$.

We note that two similar surveys have been conducted in the U.S. [39, 40]. Our instrument was developed independently for a specifically Turkish healthcare setting, but the items are derived from the same set of IOM documents and are broadly similar to the U.S. surveys. Davis and Thakkar delivered a brief 8-item survey to directors of Medical Informatics with three-level response scale (available/future implementation/no plans to implement) for each of the IOM-defined functionalities [40].We sought a more granular level of detail than that offered by this instrument. Jha et al. used a 32-item instrument, with each item reflecting one HIS function from 6 dimensions which approximate the IOM functionalities [39]. This instrument has been adapted for use in Japan, South Korea, and Spain [12, 14, 15]. Some items from the Jha survey are not appropriate for the Turkish setting, and we tailored the item selection to those most suitable to the Turkish healthcare system.

To assess the initial list of survey items, we performed a pilot study with a convenience sample of 17 QDs at hospitals across several provinces of Turkey. Staff roles in the pilot sample included physicians, nurses, computer engineers, healthcare administrators. The pilot survey was administered by email to the pilot study group and included 83 items. Each item described a core HIS function and used Likert scales to solicit opinions on the understandability and competency of each item to describe the intended HIS function. Many of these functions are either helpful or necessary to meet accreditation standards in the U.S. (e.g. by the Joint Commission), although there is no comparable national accreditation program implemented for hospitals in Turkey. Based on these pilot data, we updated the survey instrument by decreasing the number of items and revising some of the item descriptions. In particular, we removed or revised several items indicated as unclear or irrelevant based on free text comments from respondents.

The revised survey instrument includes 50 items, each of which describes a core functionality of HIS (see Additional file 1 for complete survey instrument translated from Turkish). Respondents are asked to provide two responses for each item. To reduce survey burden and complexity on respondents, we considered implementation to be 'all or nothing' and used binary responses to measure availability of core functions. The first scale measures availability of the HIS function with possible responses" : "available", "not available", or "unsure". Responses of 'unsure' were excluded and we treated availability as a binary response for all analyses. The second scale measures perceived importance of each item on the quality of healthcare provided by the hospital. This was measured on a 9-point Likert scale, with an available response of "unsure".

\section{Item classification}

Each of the 50 items was classified into one or more of the IOM domains described as follows:

1. Health Information and Data (HID): HID functions deliver critical information to providers to make clinical decisions e.g. medical and nursing diagnoses, drug allergies, problem lists, and clinical narratives. If this information is unavailable, low-quality and inefficient care may result $[38,40]$.

2. Results Management (RM): RM functions manage electronically results of all types including laboratory test results, radiology procedure results, and pathology reports. Computerized results are more accessible, timely, and accurate [38].

3. Computerized Physician Order Entry (CPOE): $\mathrm{CPOE}$ applications transmit physician orders electronically to the appropriate clinical service units [45]. The benefits of CPOE include elimination of lost or duplicate orders, improved accuracy, and reduced time to fill orders.

4. Decision Support System (DSS): DSS provides clinicians, staff, patients, or other individuals with knowledge and person-specific information to enhance health and health care. It encompasses a variety of tools and interventions such as computerized alerts and reminders, clinical guidelines, order sets, patient data reports and dashboards, documentation templates, diagnostic support, and clinical workflow tools [46]. DSS applications are embedded in the HIS and aim to detect critical situations or errors in care, and then notify the clinician perhaps with additional information to assist with clinical decisions $[4,47]$.

5. Electronic Communication and Connectivity (ECC): ECC functions include electronic communication tools such as e-mail and web messaging. These systems have been shown effective in facilitating provider communication with other providers and with patients, allowing for improved continuity of care and more timely interventions [38, 48, 49].

6. Patient Support (PS): Patient support functions involve the usage of HIT to encourage participation in patient care of patients, patient families, or third party caregivers. PS functions include patient portal, recording and monitoring patient education provided by hospital staff $[38,40]$.

7. Administrative Processes (AP): AP functions include electronic scheduling systems for admissions, inpatient and outpatient procedures, and visits. These systems increase the efficiency of hospital administration and improve the patient experience [38, 45].

8. Reporting and Population Health Management (RPHM): RPHM functions provide public and private sector reporting at the federal, state, and 
local levels for safety, quality, and public health. This may include routine reporting of key quality indicators (sometimes referred to as clinical dashboards). This reduces the data collection and reporting burden, as well as the associated costs, and would likely increase the accuracy of the data reported $[38,50]$.

\section{Data collection and analysis}

The survey was administered by email invitation and all data collected by web survey. Information and an external link to the survey were available on the Turkish $\mathrm{MoH}$ web portal accessible by the quality director or delegate at each civilian hospital in Turkey. Hospital QDs were also informed about the survey via two e-mail reminders during a two-week period in March 2015. By design, only one respondent at each hospital was permitted to submit responses.

The survey instrument contained 50 items as described above. There was a section available to record opinions and recommendations as free text (general evaluation section), and additional items on institutional, demographic, and professional characteristics including: geographic province and sector; hospital type and bed size; gender, age, educational level; job title, tenure in current hospital role, and total years of professional experience.

We calculated frequencies and percentages of respondent demographic and professional characteristics. For each HIS function, we calculated percentage of respondents indicating the function was 'available' and calculated the mean and median values of perceived impact on quality. We examined the bivariate relationship between percentage availability of each HIS function and mean perceived importance of that function using scatterplots and Pearsonian correlation analysis. We calculated mean percentage availability and importance scores averaged across all hospitals for each of the survey items (Table 3), and also averaged across items within each of the 8 IOM categories (Table 4).

We managed and analyzed data using the $\mathrm{R}$ statistical package (v3.1.0 2015 R Institute).

\section{Results}

Institutional characteristics and response rates are reported in Table 1. 1486 hospitals were invited to participate, and we collected 464 responses (overall response rate $31.2 \%$ comparable to or greater than other similar national surveys $[15,40,51])$ representing all major geographic regions and 74 of 81 (91\%) of provinces in Turkey. Response rates by section, hospital type, and bed size varied from $28.2 \%$ to $43.3 \%$. Respondent hospital bed sizes ranged from 5 (minimum) to 1218 (maximum) beds (mean 157). The majority of responses came from general hospitals with fewer than 100 beds.
Table 1 Institutional characteristics and response rates

\begin{tabular}{llll}
\hline & $\begin{array}{l}\text { Eligible Hospitals } \\
\text { in Turkey }\end{array}$ & $\begin{array}{l}\text { Number of responses } \\
\text { (\% of sample) }\end{array}$ & $\begin{array}{l}\text { Response } \\
\text { rate (\%) }\end{array}$ \\
\hline $\begin{array}{llll}\text { Hospital Sector } \\
\text { Private }\end{array}$ & 542 & $189(40.7)$ & 34.9 \\
$\begin{array}{l}\text { Ministry of Health } \\
\text { University }\end{array}$ & 874 & $252(54.3)$ & 28.8 \\
Hospital Type & 70 & $23(5.0)$ & 32.9 \\
Training Hospital & 144 & $53(11.4)$ & 36.8 \\
Specialty Hospital & 120 & $52(11.2)$ & 43.3 \\
General Hospital & 1222 & $359(77.4)$ & 29.4 \\
Number of Beds & & & \\
99 and below & 973 & $274(59.1)$ & 28.2 \\
100-199 & 241 & $88(19.0)$ & 36.5 \\
200-299 & 88 & $30(6.5)$ & 34.1 \\
300-399 & 46 & $15(3.2)$ & 32.6 \\
400 and above & 138 & $57(12.3)$ & 41.3 \\
TOTAL & 1486 & $464(100.0)$ & 31.2 \\
\hline
\end{tabular}

Our sample does not differ greatly on key characteristics from eligible hospitals in Turkey in terms of sector (chisquare $p=0.22)$ or number of beds $(p=0.12)$, although the sample slightly under-represents general hospitals ( $77 \%$ of sample, $82 \%$ of eligible hospitals, $p=0.049$ ).

The demographics and professional characteristics of the participants are shown in Table 2 . The majority of respondent QDs were female, college educated, trained as nurses, under the age of 40, with fewer than 10 years professional experience and hospital tenure.

Availability and mean perceived importance are reported for all 50 items (Table 3). Mean perceived importance was 7.87 (SD 1.71). Across all items, we observed lowest and highest means respectively of 7.13 (SD 2.25) (Item 2: predict time to examination on admission) and 8.41 (SD 1.81) (Item 50: data security). Availability of HIS functions, averaged across all 50 items and across all hospitals, was $65.6 \%$ (SD 20.0), with availability on particular functions ranging from 19.6\% (SD 39.5) (item 15: telemedicine applications) to $97.4 \%$ (SD 16.0) (item 49: authorized access for staff). Respondent QDs reported that all HIS functions surveyed have an important effect on quality and patient safety (mean 7.87 on 9-point scale, SD 1.71).

We plotted the bivariate relationship between availability and perceived importance of HIS functions (Fig. 1). Availability and mean perceived importance are moderately correlated $(r=0.52, p=0.0001)$. Functions with highest availability and perceived importance were those related to data security (items 49,50 ) and laboratory services (items 8,10 ), while those with lowest availability and perceived importance related to telemedicine (item 15) and patient education (items 28, 29). Functions 
Table 2 Respondent demographics

\begin{tabular}{|c|c|}
\hline Demographic features & Frequency (\%) \\
\hline \multicolumn{2}{|l|}{ Gender } \\
\hline Female & $314(67.7)$ \\
\hline Male & $150(32.3)$ \\
\hline \multicolumn{2}{|l|}{ Education } \\
\hline High school & $18(3.9)$ \\
\hline Associate Degree & $69(14.9)$ \\
\hline Bachelor Degree & $211(45.5)$ \\
\hline Master & $110(23.7)$ \\
\hline $\mathrm{PhD}$ & $10(2.2)$ \\
\hline Medical Specialist & $19(4.1)$ \\
\hline Missing & $27(5.8)$ \\
\hline \multicolumn{2}{|l|}{ Job } \\
\hline Physician & $42(9.1)$ \\
\hline Nurse & $235(50.6)$ \\
\hline Other Healthcare Staff & $41(8.8)$ \\
\hline Engineer & $11(2.4)$ \\
\hline Administrative Staff & $101(21.8)$ \\
\hline Missing & $34(7.3)$ \\
\hline \multicolumn{2}{|l|}{ Age Groups } \\
\hline $20-24$ & $15(3.2)$ \\
\hline $25-29$ & $50(10.8)$ \\
\hline $30-34$ & $95(20.5)$ \\
\hline $35-39$ & $104(22.4)$ \\
\hline $40-44$ & $70(15.1)$ \\
\hline $45-50$ & $36(7.8)$ \\
\hline 50 and above & $22(4.7)$ \\
\hline Missing & $72(15.5)$ \\
\hline \multicolumn{2}{|c|}{ Experience in current hospital work area/unit } \\
\hline $0-5$ years & $210(45.3)$ \\
\hline $6-10$ years & $75(16.2)$ \\
\hline $11-15$ years & $46(9.9)$ \\
\hline $16-20$ years & $28(6.0)$ \\
\hline $21-25$ years & $7(1.5)$ \\
\hline 26 years and above & $4(0.9)$ \\
\hline Missing & $94(20.3)$ \\
\hline \multicolumn{2}{|l|}{ Experience in profession } \\
\hline $0-5$ years & $94(20.3)$ \\
\hline $6-10$ years & $78(16.8)$ \\
\hline $11-15$ years & $59(12.7)$ \\
\hline $16-20$ years & $53(11.4)$ \\
\hline $21-25$ years & $45(9.7)$ \\
\hline 26 years and above & $32(6.9)$ \\
\hline Missing & $103(22.2)$ \\
\hline
\end{tabular}

related to staff safety (items 34 and 44), medication safety (items 1, 24, 25, 26), and monitoring indicators (item 33) were less available than expected relative to their perceived importance. Conversely, functions related to patient access, comfort, and rights (items 2, 3, 5, 6) and operational activities (items 4, 12, 46) had lower perceived importance than we would expect based on availability.

We categorized all 50 items into eight non-exclusive IOM categories of HIT functionality (Additional file 1) and ranked the availability of functions within these domains from highest to lowest (Table 4). Functions related with result management (89.3\%) and decision support systems (52.2\%) had the highest and lowest reported availability score respectively. Respondent QDs reported functions related with $\mathrm{CPOE}$ to have the highest importance in terms of improving healthcare quality, while functions related with patient support were ranked as lowest.

Free text comments are classified and sorted by frequency (Table 5). Many respondents highlighted the importance of the study, their desire to review HIS from the perspective of quality and patient safety, and higher expectations of HIS functions to improve quality and patient safety.

\section{Discussion}

We investigated availability of HIS functions and their perceived importance on quality and patient safety by 50 items survey developed by authors, and received responses from hospital quality professionals from a broadly representative sample of Turkish hospitals in terms of geographic and institutional characteristics. Despite high levels of perceived importance across all 50 HIS functions which comprised our survey, on average only two-thirds of hospitals surveyed have adopted these functions and important functions like decision support systems are adopted at very low rates.

We focused on subgroups of HIS functions that are of special interest. First we considered the more highly available functions. Generally the most widely available functions are those related to data security, automation of laboratory processes, and administrative reporting. Reasons for this high adoption may include the importance of privacy and data security in the healthcare setting [52, 53]; pressure on laboratories to satisfy ongoing quality audits and maintain licensing or certification; or recommendations from $\mathrm{MoH}$ [54-56]. It is also worth noting that administrative functions are often highly valued by hospital leaders who are in a position to influence HIS purchasing decisions $[6,45,57]$.

We examined more closely the relationship between availability and perceived importance of each item. We observed as expected that availability and perceived 
Table 3 Average of availability and percieved importance [mean (SD)]

\begin{tabular}{|c|c|c|c|}
\hline Item No & HIS functions & Availability (\%) & Perceived importance (Over 9) \\
\hline 1 & $\begin{array}{l}\text { Display alerts for high risk medications } \\
\text { (e.g. narcotics, sound-alike drugs, concentrated electrolytes) } \\
\text { just prior to administration }\end{array}$ & $47.7(50.0)$ & $8.07(2.05)$ \\
\hline 2 & Predict time to patient examination on admission & $74.6(43.6)$ & $7.13(2.25)$ \\
\hline 3 & Record time to consultation after request from emergency department & $82.4(38.2)$ & $7.66(2.13)$ \\
\hline 4 & Display real-time availability of patient beds & $91.9(27.4)$ & $7.84(1.99)$ \\
\hline 5 & Flag and prioritize elderly and disabled patients & $80.8(39.4)$ & $7.81(1.99)$ \\
\hline 6 & $\begin{array}{l}\text { Provide electronic copy of patient records when requested } \\
\text { (e.g. diagnosis list, lab test results, administered procedures, } \\
\text { administered medications, discharge summary) }\end{array}$ & $82.9(37.7)$ & $7.58(2.02)$ \\
\hline 7 & $\begin{array}{l}\text { View all diagnostic test results including laboratory, radiology, pathology, } \\
\text { nuclear medicine, endoscopy }\end{array}$ & $92.4(26.5)$ & $8.12(1.85)$ \\
\hline 8 & $\begin{array}{l}\text { Record times and performing staff of laboratory test samples throughout } \\
\text { all laboratory phases i.e. sampling, accepting, analyzing, approving, and reporting }\end{array}$ & $96.1(19.4)$ & $8.19(1.79)$ \\
\hline 9 & Display alerts for lab samples that do not meet acceptance criteria & $72.4(44.8)$ & $7.96(1.98)$ \\
\hline 10 & Display alerts for laboratory tests that return panic values & $96.5(18.4)$ & $8.33(1.79)$ \\
\hline 11 & $\begin{array}{l}\text { Display reminders for internal and external lab quality control measures and } \\
\text { keep their result for analyses }\end{array}$ & $57.8(49.4)$ & $7.65(2.12)$ \\
\hline 12 & Record laboratory process problems (pre-analytic, analytic, and post-analytic) & $71.0(45.4)$ & $7.76(2.02)$ \\
\hline 13 & $\begin{array}{l}\text { Provide digital radiology images within internal network i.e. Picture Archiving } \\
\text { and Communication System (PACS) }\end{array}$ & $85.3(35.5)$ & $8.18(1.89)$ \\
\hline 14 & Monitor radiology appointment and reporting times & $61.1(48.8)$ & $7.46(2.13)$ \\
\hline 15 & Support telemedicine applications & $19.6(39.5)$ & $7.58(2.28)$ \\
\hline 16 & $\begin{array}{l}\text { Monitor use of blood and blood products during order, preparation, } \\
\text { acceptance, and implementation }\end{array}$ & $74.3(43.8)$ & $8.11(1.90)$ \\
\hline 17 & Monitor blood and blood products stock and expiration date & $78.1(41.4)$ & $8.16(1.91)$ \\
\hline 18 & Record disease severity as structured data (e.G. apache II, SAPS II, and PRISM) & $50.7(50.1)$ & $7.64(2.10)$ \\
\hline 19 & Integrate nursing care plans into medical record & $58.5(49.3)$ & $7.57(2.26)$ \\
\hline 20 & $\begin{array}{l}\text { Record and integrate all clinical orders into medical record including } \\
\text { laboratory test orders, medication orders, nursing care orders, nutrition } \\
\text { therapy orders, rehabilitation therapy orders }\end{array}$ & $84.2(36.5)$ & $7.94(1.99)$ \\
\hline 21 & $\begin{array}{l}\text { Record and integrate all diagnostic, clinical, and surgical procedures into } \\
\text { medical record including endoscopy, cardiac catheterization, radiotherapy, } \\
\mathrm{CT} \text {, and ultrasound }\end{array}$ & $90.1(29.9)$ & $8.05(1.95)$ \\
\hline 22 & $\begin{array}{l}\text { Record usage and monitor complications of anesthetic agents and sedatives } \\
\text { administered outside of anesthesiology (e.g. endoscopy, cardiac catheterization, } \\
\text { and IVF units) }\end{array}$ & $52.2(50.0)$ & $7.81(2.08)$ \\
\hline 23 & Display clinical guidelines and provide alerts for deviations & $50.2(50.1)$ & $7.53(2.10)$ \\
\hline 24 & Provide alerts for drug-drug interactions & $45.5(49.9)$ & $7.98(2.06)$ \\
\hline 25 & Provide alerts for drug-food interactions & $42.3(49.5)$ & $7.88(2.12)$ \\
\hline 26 & Provide alerts for drug-allergy interactions & $41.9(49.4)$ & $8.07(2.06)$ \\
\hline 27 & Integrate Computerized Physician Order Entry & $75.6(43.0)$ & $8.04(1.98)$ \\
\hline 28 & Provide alerts for patient education that is part of care plan or discharge plan & $29.7(45.8)$ & $7.39(2.23)$ \\
\hline 29 & Record all patient education provided to patient & $41.8(49.4)$ & $7.32(2.18)$ \\
\hline 30 & Record patient and staff safety events & $57.0(49.6)$ & $7.86(2.11)$ \\
\hline 31 & $\begin{array}{l}\text { Record emergency code alerts (e.g. Code Blue, Code White) and integrate } \\
\text { with paging system }\end{array}$ & $42.6(49.5)$ & $7.67(2.22)$ \\
\hline 32 & Record blood transfusion reactions as structured data & $52.0(50.0)$ & $7.84(2.17)$ \\
\hline 33 & Monitor hospital key performance indicators automatically & $62.6(48.5)$ & $7.96(2.00)$ \\
\hline 34 & Flag patients and warn staff of patients with risk of infection (e.g. HIV+, $\mathrm{HepC}+$ ) & $51.7(50.0)$ & $8.18(2.04)$ \\
\hline
\end{tabular}


Table 3 Average of availability and percieved importance [mean (SD)] (Continued)

\begin{tabular}{|c|c|c|c|}
\hline Item No & HIS functions & Availability (\%) & Perceived importance (Over 9) \\
\hline 35 & $\begin{array}{l}\text { Monitor nosocomial infections and transmit surveillance data to national or } \\
\text { international networks }\end{array}$ & $44.8(49.8)$ & $7.83(2.13)$ \\
\hline 36 & $\begin{array}{l}\text { Monitor and record sterilization processes including procedure date and time } \\
\text { and material expiration date }\end{array}$ & $32.8(47.0)$ & $7.76(2.19)$ \\
\hline 37 & $\begin{array}{l}\text { Display real-time information necessary for unit managers including bed occupancy, } \\
\text { waiting list, surgeries scheduled }\end{array}$ & $88.9(31.5)$ & $7.85(2.01)$ \\
\hline 38 & $\begin{array}{l}\text { Report periodically on operational statistics including monthly admissions, } \\
\text { income-expenditure, services delivered }\end{array}$ & $94.5(22.8)$ & $7.88(1.94)$ \\
\hline 39 & Provide alerts for devices that require periodic maintenance or calibration & $29.5(45.7)$ & $7.76(2.11)$ \\
\hline 40 & $\begin{array}{l}\text { Provide alerts for medications and medical supplies near expiration or at critically } \\
\text { low stock levels }\end{array}$ & $91.9(27.3)$ & $8.25(1.85)$ \\
\hline 41 & Provide inventory of all medical devices including location and responsible staff & $57.4(49.5)$ & $7.65(2.08)$ \\
\hline 42 & Monitor and provide reminders for routine health screening of clinical staff & $25.6(43.7)$ & $7.80(2.13)$ \\
\hline 43 & Identify, flag, and, prohibit duplicate patient records & $83.0(37.6)$ & $8.14(1.95)$ \\
\hline 44 & Monitor occupational accidents and injuries & $52.0(50.5)$ & $7.90(2.10)$ \\
\hline 45 & $\begin{array}{l}\text { Display current organizational policies and procedures and provide alerts of } \\
\text { updated documents }\end{array}$ & $67.5(46.9)$ & $7.90(2.09)$ \\
\hline 46 & Record clinical staff certification and licensing information & $78.8(40.9)$ & $7.80(1.97)$ \\
\hline 47 & Integrate and update information with hospital external website & $56.1(49.7)$ & $7.73(2.10)$ \\
\hline 48 & Provide online patient portal to view, download, and transmit lab results & $91.1(28.5)$ & $8.09(1.86)$ \\
\hline 49 & Provide access control management for different staff groupings & $97.4(16.0)$ & $8.18(1.85)$ \\
\hline \multirow[t]{2}{*}{50} & Provide data security and protection for electronic health information & $93.6(24.5)$ & $8.41(1.81)$ \\
\hline & Average & $65.6(20.0)$ & $7.87(1.71)$ \\
\hline
\end{tabular}

importance are generally correlated (Fig. 1). However there were some functions that departed from the general pattern. For example, we identified three 'clusters' of items which were generally not as available as their perceived importance would suggest: staff safety, medication safety, and monitoring indicators. While focus has recently shifted to patient-centered care, it is also increasingly recognized that high quality care includes employee safety as well as patient safety. This change of emphasis is meant to ensure that a safety

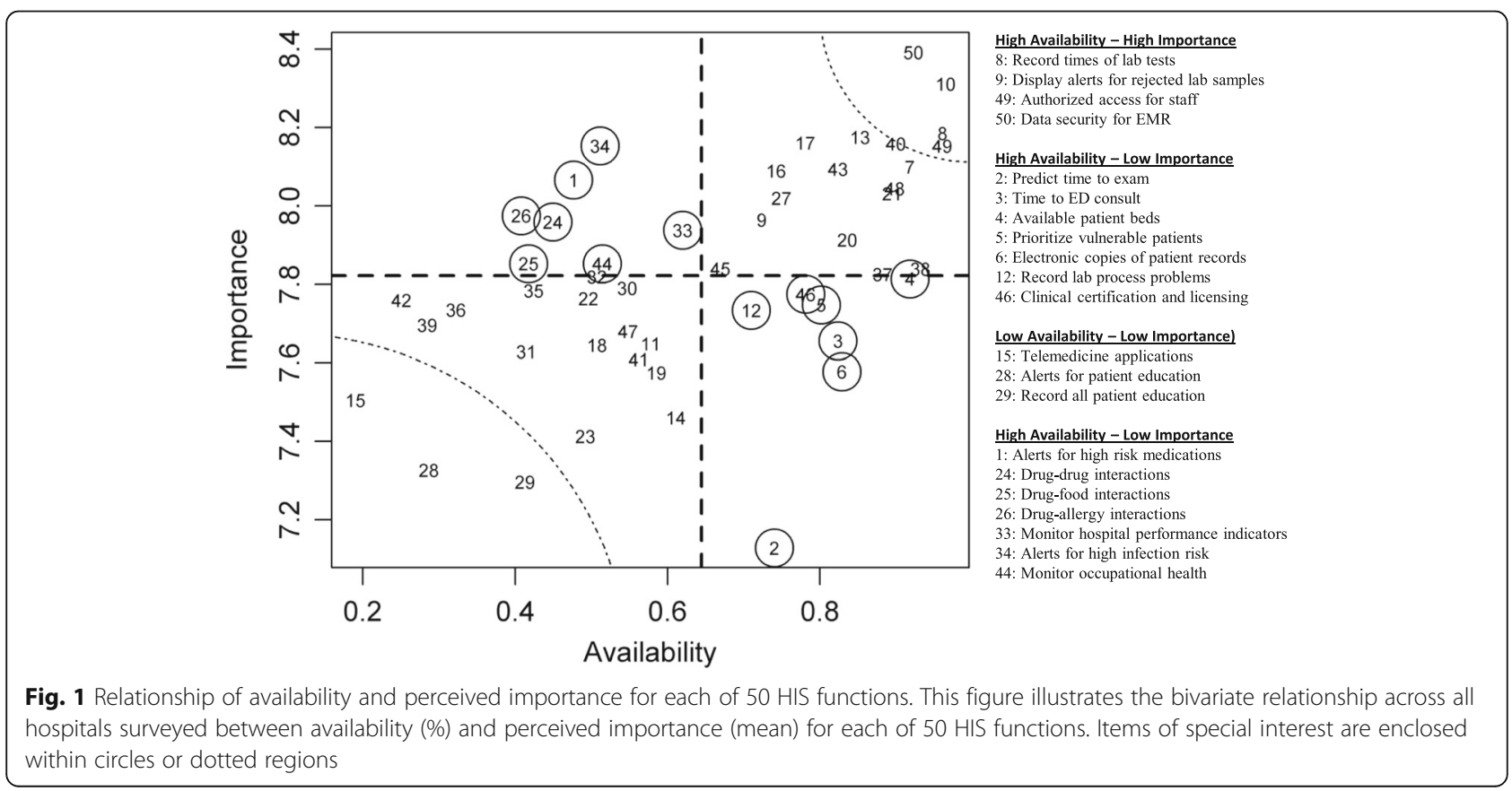


Table 4 Availability and perceived importance by IOM classification [mean (SD)]

\begin{tabular}{lll}
\hline & Availability (\%) & Perceived importance \\
\hline Result Management & $89.3(18.5)$ & $7.87(1.72)$ \\
Administrative Processes & $71.7(18.7)$ & $7.86(1.71)$ \\
$\begin{array}{l}\text { Computerized Physician } \\
\text { Order Entry }\end{array}$ & $68.0(25.1)$ & $7.93(1.80)$ \\
$\begin{array}{l}\text { Electronic Communication } \\
\text { and Connectivity }\end{array}$ & $64.2(21.3)$ & $7.87(1.72)$ \\
$\begin{array}{l}\text { Reporting and Population } \\
\text { Health Management }\end{array}$ & $63.0(24.5)$ & $7.79(1.78)$ \\
$\begin{array}{l}\text { Health Information and Data } \\
\text { Patient Support }\end{array}$ & $62.6(24.0)$ & $7.89(1.75)$ \\
Decision Support Systems & $62.5(27.1)$ & $7.67(1.76)$ \\
\hline
\end{tabular}

culture pervades a healthcare organization, with the safety of the workforce and the work environment given equal standing as a safety priority [58]. Medication errors compose a sizable proportion of the total burden of medical errors, and information systems are an effective tool to prevent these errors $[2,3,59,60]$. Monitoring indicators in real-time using HIS offers many advantages $[61,62]$. This reflects discordance between hospital QDs and the hospital leaders who make decisions about HIS purchasing.

Table 5 Comments collected from the "general evaluation" section

\begin{tabular}{|c|c|}
\hline Participant comments & Frequency \\
\hline $\begin{array}{l}\text { Thanks for the study and for the opportunity to } \\
\text { evaluate HIS functionalities currently in use }\end{array}$ & 33 \\
\hline $\begin{array}{l}\text { Every HIS function in survey would positively affect } \\
\text { quality of healthcare }\end{array}$ & 22 \\
\hline $\begin{array}{l}\text { Some functions are available as a part of our HIS, } \\
\text { but they are not used }\end{array}$ & 14 \\
\hline $\begin{array}{l}\text { Turkish MoH should produce and share HIS for } \\
\text { common use }\end{array}$ & 12 \\
\hline $\begin{array}{l}\text { HIT department support is insufficient, ineffective, or } \\
\text { disregards users; technical problems lead to } \\
\text { sub-optimal use }\end{array}$ & 12 \\
\hline $\begin{array}{l}\text { Every HIS function in survey should be mandatory } \\
\text { for every HIS }\end{array}$ & 10 \\
\hline $\begin{array}{l}\text { Employees and managers lack training and experience } \\
\text { to use HIS effectively }\end{array}$ & 7 \\
\hline $\begin{array}{l}\text { MoH should define certification standards for HIS } \\
\text { and related products }\end{array}$ & 5 \\
\hline $\begin{array}{l}\text { Comments about specific functions (PACS, telemedicine, } \\
\text { monitoring indicators, nursing care plans) }\end{array}$ & 5 \\
\hline $\begin{array}{l}\text { Suggested HIS functions related to quality and patient } \\
\text { safety not included in survey }\end{array}$ & 5 \\
\hline $\begin{array}{l}\text { National integration of HIS and patient records available } \\
\text { to all healthcare institutions }\end{array}$ & 3 \\
\hline $\begin{array}{l}\text { Integration problems between information systems used } \\
\text { by } \mathrm{MoH} \text { and hospitals }\end{array}$ & 3 \\
\hline Total & 131 \\
\hline
\end{tabular}

Functions associated with patient access to services, patient comfort, patient rights, and hospital operations were evaluated as relatively less important than their availability. Indeed, QDs are expected to be more sensitive to patient satisfaction and patient experience. However our findings suggest that the administrator responsible for HIS selection might prioritize administrative needs and patient expectations driven by previously determined health policies [63] that might lead to diminished perceived importance among healthcare staff include quality directors.

Availability and perceived importance were concordant and generally high for features related to information security, patient safety, and laboratory services. Information security is a top priority for every institution and especially for hospitals, although there are no privacy laws in Turkey specific to healthcare such as the Health Information Portability Accountability Act (HIPAA). Moreover, patient safety and laboratory services standards were component of national quality standards from the first iteration, and hospitals have been surveyed against these standards several times [54, 64]. These findings are consistent with a positive effect from the quality survey process explained above.

Telemedicine applications and patient education functions had generally low availability and perceived importance. Although telemedicine has significant advantages for patients located in remote geographic regions far from qualified healthcare facilities [65-68], our finding is not surprising since many hospitals without remotely located patients may consider telemedicine a luxury. Patient empowerment via education is understood to be an important part of the healing process $[69,70]$. We believe our findings have identified an important issue for further discussion among healthcare administrators and employees.

The IOM category reported most available was RM, with these functions present on average across $90 \%$ of respondent hospitals. Managing results electronically has substantial impact on unnecessarily ordered tests, and timeliness of reporting to providers. It is also significant to prevent medical errors [71-73]. The high level of RM function adoption among Turkish hospitals may accelerate future plans for electronic medical records shared throughout all Turkish healthcare providers, leading to eventual improvements in clinical care by increasing provider access to timely and accurate clinical data. Conversely, DSS is reported as the functional category least available in Turkish hospitals. DSS includes applications that combine clinical information with embedded medical knowledge to assist the human decision process [4]. These systems imply some higher level of information processing, or inference, by the computer [74]. Some respondents reported that both providers and hospital managers lacked the necessary knowledge 
for effective use of information systems (See Table 5). Thus general issues of staff training and expertise of management may explain lower availability of DSS in Turkish hospitals, as well as clinicians' willingness to ask, direct, and help vendors and hospital managers with the development and adoption of DSS. The literature supports the potential of DSS to improve patient safety and quality of care e.g. reminders for vital tasks, assistance with diagnoses, avoiding drug-drug interactions, enhancing clinical regulatory compliance, reducing unnecessary test orders, and identifying emerging disease outbreaks [6, 74-76]. Involving clinicians in DSS development, and increased awareness and investment in DSS will likely improve safety and quality across the Turkish hospital system.

Perceived importance was generally high across all items, and there were no substantial differences in across IOM categories. CPOE functions were perceived as most important and PS functions (e.g. patient portal) were generally perceived as less important. Similar research studying 89 U.S. healthcare facilities in 2005 rated categories 7.58 to 8.83 (out of 10) on importance, similar to our results. PS shows low in the U.S. as well as Turkey [40]. The same study showed $37 \%$ of respondents report current use of at least one component in all of the eight core HIS functionalities, while another study suggests that in 2009 , only $1.5 \%$ of U.S. hospitals had comprehensive HIS i.e. present in all clinical units, and only an additional $7.6 \%$ have a basic system i.e. present in at least one clinical unit. Results from the U.S., Spain, and South Korea also show highest availability for RM functionality e.g. RM was available for $75 \%$ of U.S. hospitals $[14,15,39]$. There are broad parallels between the U.S. situation circa 2010 and the adoption of HIS in Turkey roughly 5 years later.

This study has several limitations. Although we examined reliability of individual items, we did not validate our survey using an independent sample nor did we validate against an existing instrument. We designed and piloted our survey with an aim of face validity, and our focus was on broad patterns of response rather than the psychometric properties of the survey instrument. The survey instrument does not include all HIS functions but rather 50 items to be most relevant to patient safety and quality as determined by researcher judgment and pilot testing. Although observed scores for perceived importance lie within a compressed range of values - mean responses across items range from 7.13 to 8.44 - our large sample allows for valid statistical comparison and correlation. Military hospitals were not included in the sample. Finally, promotion of the survey via the $\mathrm{MoH}$ e-mail and website may have induced a 'halo effect' of positive response bias.
Diverse HIS functions have been adopted at different rates in Turkey and across the world. This study, which supports previous research conducted in the U.S., presents potentially useful insight into the adoption of HIS functions to support patient safety and quality. Findings from this and similar surveys should be considered carefully by policymakers, software designers, clinicians, and hospital leaders. We recommend mandating certified software (or offering incentives) and surveying HIS functions during regular quality audits, two policy approaches which would support system-wide improvements. Another important issue that we identified is the training of hospital leaders and clinical staff. Technical support and training processes may be better defined by public regional authorities. Software designers may consider our results when developing HIS products and hospital leaders should make HIS purchasing decisions using information from QDs on which functions are perceived most important to patient safety and quality of care.

\section{Conclusions}

Our study corroborates previous work highlighting the perceived importance of HIT on quality and patient safety. After revision and tailoring to the specifics of other international settings, the expanded list of items in this study could be used elsewhere to increase awareness and to survey availability of HIS functions in other national healthcare systems. We believe that our survey is an important first step to understand the system-wide availability of specific HIS functions across hospitals in Turkey, and that similar surveys in other countries would yield valuable knowledge to guide policymakers and hospital leaders in many settings.

Our findings support the conclusion that HIS functions in Turkish hospitals are generally not as available as quality managers would like. Policymakers, hospital leaders, and software developers all have a potential role to address future improvements. Some policy levers include financial incentives to adopt specific HIS functions; government involvement in certification of software; regulations to encourage or enforce usage of certified HIS; and inclusion of desired functions into accreditation manuals. Each of these policies may help integrate HIS functions to support quality and patient safety in Turkish hospitals. Finally, further investment in training programs will be needed across organizational levels, including clinical employees, HIT support staff, and hospital leaders and managers.

\section{Endnotes}

${ }^{1}$ Terms such as Hospital Information System (HIS), Electronic Medical Record (EMR), Electronic Health Record (EHR), and Patient Health Record (PHR) are 
used interchangeably in the literature. We have tried to use the term Hospital Information System (HIS) consistently throughout this paper unless it is necessary or relevant to differentiate terms.

${ }^{2}$ These terms are translated from Turkish responses "var", "yok", and "fikrim yok".

\section{Additional file}

Additional file 1: Survey Items Related to IOM Groups. This table provides classification of survey items within the 8 HIS functionality categories described by IOM. (XLSX $13 \mathrm{~kb}$ )

\begin{abstract}
Abbreviations
AP: Administrative Processes; APACHE: Acute physiology and chronic health evaluation; CMS: Centers for Medicare and Medicaid Services; CPOE: Computerized physician order entry; CT: Computed tomography; DSS: Decision support system; ECC: Electronic communication and connectivity; EHR: Electronic health records; EMR: Electronic medical record; HepC: Hepatitis C; HID: Health information and data; HIPAA: Health Information Portability Accountability Act; HIS: Hospital information systems; HIT: Health information technology; HIV: Human immunodeficiency virus; ICT: Information and communication technology; IOM: Institute of Medicine; IVF: In vitro fertilization; MoH: Ministry of Health; PACS: Picture Archiving And Communication System; PRISM: Pediatric risk of mortality; PS: Patient support; QDs: Quality directors; RM: Result management; RPHM: Reporting and population health management; SAPS: Simplified acute physiology score; SD: Standard deviation; U.K.: United Kingdom; U.S.: United States
\end{abstract}

\section{Acknowledgements}

This research was supported by Turkish Ministry of Health, Department of Quality and Accreditation in Healthcare. We thank our colleagues from Department of Quality and Accreditation in Healthcare who provided assistance with collecting research data, although they may not agree with all of the interpretations and conclusions of this paper.

\section{Funding}

Not applicable

\section{Availability of data and materials}

The datasets generated and/or analyzed during the current study are not publicly available because the data were collected as part of a confidential survey of hospital employees. Some data collected could potentially identify respondents and/or their institutions.

\section{Authors' contributions}

MS: conceived of and designed the study, performed the literature review, created and implemented the survey, analyzed the data, and drafted the manuscript text. AO: supervised the study, assisted with statistical analyses, contributed to the writing and editing of the manuscript text, and reviewed and approved its final version. Both the authors read and approved the final version of the manuscript.

\section{Ethics approval and consent to participate}

Approval was granted by Hacettepe University in 2011 to conduct this research including collection and analysis of the quality improvement data without ethics committee review. There were no published formal guidelines on waiver of ethical review at that time. Current guidelines are available here: http://www.etikkurul.hacettepe.edu.tr/yerel/yonerge.php We requested informed assent for participation from survey respondents along with a brief explanation of the study during the initial page of the web survey. Participants who completed the web survey were assumed to consent to the survey.

\section{Consent for publication}

Not applicable

\section{Competing interests}

The authors declare that they have no competing interests.

\section{Publisher's Note}

Springer Nature remains neutral with regard to jurisdictional claims in published maps and institutional affiliations.

\section{Author details}

${ }^{1}$ Center for Applied Pediatric Quality Analytics, Boston Children's Hospital, 300 Longwood Avenue, Boston, MA 02115, USA. ²Department of Pediatrics, Harvard Medical School, Boston, MA, USA.

Received: 15 May 2017 Accepted: 2 January 2018

Published online: 12 January 2018

References

1. IOM: The quality of health Care in America. 2013. http://www. nationalacademies.org/hmd/Activities/Quality/QualityHealthCareAmerica. Accessed 02 July 2014.

2. IOM. Crossing the quality chasm: a new health system for the 21 st century. Washington (DC): National Academy Press; 2001

3. IOM. To err is human: building a safer health system. Washington (DC): National Academy Press; 1999.

4. Hersh WR. Medical informatics: improving health care through information. JAMA. 2002;288:1955-8.

5. Abbott $P$, Taylor LA. The role of health information Technology in Improving Healthcare Quality and Patient Safety: Johns Hopkins University School of Nursing; 2007. p. 1-4.

6. Chaudhry B, Wang J, Wu S, Maglione M, Mojica W, Roth E, Morton SC, Shekelle PG. Systematic review: impact of health information technology on quality, efficiency, and costs of medical care. Ann Intern Med. 2006;144:742-52.

7. Chassin MR, Galvin RW. The urgent need to improve health care quality. Institute of Medicine National Roundtable on health care quality. JAMA. 1998;280:1000-5.

8. Luchenski SA, Reed JE, Marston C, Papoutsi C, Majeed A, Bell D. Patient and public views on electronic health records and their uses in the United kingdom: cross-sectional survey. J Med Internet Res. 2013; https://doi.org/10. 2196/jmir.2701.

9. Nohr C, Andersen SK, Bernstein K, Bruun-Rasmussen M, Vingtoft S. Diffusion of electronic health records-six years of empirical data. Stud Health Technol Inform. 2007;129:963-7.

10. Urowitz S, Wiljer D, Apatu E, Eysenbach G, Delenardo C, Harth T, Pai H, Leonard KJI. Canada ready for patient accessible electronic health records? A national scan. BMC Med Inform Decis Mak. 2008:8:1472-6947.

11. Kaipio J, Laaveri T, Hypponen H, Vainiomaki S, Reponen J, Kushniruk A, Borycki E, Vanska J. Usability problems do not heal by themselves: national survey on physicians' experiences with EHRs in Finland. Int J Med Inform. 2017:97:266-81.

12. Inokuchi R, Sato H, Nakamura K, Aoki Y, Shinohara K, Gunshin M, Matsubara T, Kitsuta Y, Yahagi N, Nakajima S. Motivations and barriers to implementing electronic health records and ED information systems in Japan. Am J Emerg Med. 2014; https://doi.org/10.1016/j.ajem.2014.03.035.

13. Heimly V, Grimsmo A, Faxvaag A. Diffusion of electronic health records and electronic communication in Norway. Applied clinical informatics. 2011; https://doi.org/10.4338/ACl-2011-01-IE-0008.

14. Kim YG, Jung K, Park YT, Shin D, Cho SY, Yoon D, Park RW. Rate of electronic health record adoption in South Korea: a nation-wide survey. Int J Med Inform. 2017; https://doi.org/10.1016/j.jimedinf.2017.02.009.

15. Marca G, Perez A, Blanco-Garcia MG, Miravalles E, Soley P, Ortiga B. The use of electronic health records in Spanish hospitals. Him J. 2014;43:37-44.

16. Vafaee A, Vahedian M, Esmaeily $H$, Kimiafar K. Views of users towards the quality of hospital information system in training hospitals. Journal of research in health sciences. 2010;10:47-53.

17. E.U. eHealth action plan 2012-2020-innovative healthcare for the 21st century. 2012

18. Ortiz E, Clancy CM. Use of information technology to improve the quality of health care in the United States. Health Serv Res. 2003; https://doi.org/10. 1111/1475-6773.00127.

19. Nguyen L, Bellucci E, Nguyen LT. Electronic health records implementation: an evaluation of information system impact and contingency factors. Int J Med Inform. 2014;83:779-96. 
20. Bates DW, Pappius E, Kuperman GJ, Sittig D, Burstin H, Fairchild D, Brennan TA, Teich JM. Using information systems to measure and improve quality. Int J Med Inform. 1999; https://doi.org/10.1016/S1386-5056(98)00152-X.

21. Bates DW, Pappius EM, Kuperman GJ, Sittig D, Burstin H, Fairchild D, Brennan TA, Teich JM. Measuring and improving quality using information systems. Stud Health Technol Inform. 1998;2:814-8.

22. Nirel N, Rosen B, Sharon A, Blondheim O, Sherf M, Samuel H, Cohen AD. The impact of an integrated hospital-community medical information system on quality and service utilization in hospital departments. Int J Med Inform. 2010; https://doi.org/10.1016/j.ijmedinf.2010.06.005.

23. Hillestad R, Bigelow J, Bower A, Girosi F, Meili R, Scoville R, Taylor R. Can electronic medical record systems transform health care? Potential health benefits, savings, and costs. Health Aff. 2005:24:1103-17.

24. Sağıroğlu YÖ. Implementation difficulties of hospital information systems: a case study in a private Hospital in Turkey. İstanbul: Bogaziçi University; 2006.

25. HealthlT.gov: EHR Incentives \& Certification. http://www.healthit.gov/providersprofessionals/ehr-incentives-certification (2014). Accessed 16 Apr 2015.

26. David B, Tavenner M. The "meaningful use" regulation for electronic health records. N Engl J Med. 2010;363:501-4.

27. HRSA: What is "meaningful use". 2015. https://www.cms.gov/Regulationsand-Guidance/Legislation/EHRIncentivePrograms/downloads/MU_Stage1_ ReqOverview.pdf. Accessed 16 Apr 2015.

28. Black AD, Car J, Pagliari C, Anandan C, Cresswell K, Bokun T, McKinstry B, Procter R, Majeed A, Sheikh A. The impact of eHealth on the quality and safety of health care: a systematic overview. PLoS Med. 2011; https://doi. org/10.1371/journal.pmed.1000387.

29. Haux R, Winter A, Ammenwerth E, Brigl B. Strategic information Management in Hospitals. An introduction to hospital information systems. New York: Springer; 2004.

30. Haux R. Health information systems- past, present, future. Int J Med Inform. 2006;75:268-81.

31. Takeda H, Matsumura Y, Nakajima K, Kuwata S, Zhenjun Y, Shanmai J, Qiyan Z, Yufen C, Kusuoka H, Inoue M. Health care quality management by means of an incident report system and an electronic patient record system. Int J Med Inform. 2003:69:285-93.

32. WHO. Global diffusion of eHealth: making universal health coverage achievable. Report of the third global survey on eHealth. Genova: world health. Organization. 2016;

33. Anderson JG. Social, ethical and legal barriers to e-health. Int J Med Inform. 2007;76:480-3.

34. HealthlTDashboard: Quick Stats. https://dashboard.healthit.gov/quickstats/ quickstats.php (2017). Accessed 5 Jan 2017.

35. Borycki EM, Newsham D, Bates DW. eHealth in North America. Yearb Med Inform. 2013;8:103-6.

36. Hyppönen $\mathrm{H}$, Kangas M, Reponen J, Nøhr C, Villumsen S, Koch S, Hardardottir GA, Gilstad H, Jerlvall L, Pehrsson T. Nordic eHealth benchmarking: Nordic Council of Ministers; 2015.

37. WHO. Atlas of eHealth country profiles: the use of eHealth in support of universal health coverage: based on the findings of the third global survey on eHealth 2015. Geneva, Switzerland: World Health Organization. p. 2016

38. IOM. Key Capabilities of an electronic health record system letter report. USA: National Academy of Sciences; 2003.

39. Jha AK, DesRoches CM, Campbell EG, Donelan K, Rao SR, Ferris TG, Shields A, Rosenbaum S, Blumenthal D. Use of electronic health records in U.S. hospitals. N Engl J Med. 2009;360:1628-38.

40. Davis DC, Thakkar M. Perceived level of benefits and risk Core functionalities of an EHR system. In: Joseph T, editor. Healthcare information systems and informatics: research and practices. New York: Information Science Publishing; 2008. p. 297-312

41. TurkeyMoH. Healthcare quality standards-hospital. Ankara: Pozitif Matbaa; 2016.

42. Taylan G, EB BI, Naldöken Ü. Determination of profiles of quality directors who work for Turkey Ministry of Health hospitals. In: Ünal D, Okumuş N, editors. VI International conference on healthcare performance and quality. Antalya, Turkey: Miki Matbaacılık San. ve Tic. Ltd. şti; 2016

43. CMS: Medicare \& Medicaid EHR incentive program meaningful use stage 1 requirements overview. http://www.cms.gov/Regulations-and-Guidance/ Legislation/EHRIncentivePrograms/downloads/MU_Stage1_ReqOverview.pdf 2010. Accessed 18 Apr 2015.

44. International JC. Joint commission international accreditation standards for hospitals. 5th ed: Joint Commission Resources; 2013.
45. Glandon GL, Smaltz DH, Slovensky JD. Austin and Boxerman's Information systems for healthcare. Chicago: AUPHA Health Administration Press; 2008.

46. Osheroff JA, Teich JM, Middleton B, Steen EB, Wright A, Detmer DE. A roadmap for National Action on clinical decision support. J Am Med Inform Assoc. 2007; https://doi.org/10.1197/jamia.M2334.

47. Bright TJ, Wong A, Dhurjati $R$, et al. Effect of clinical decision-support systems: a systematic review. Ann Intern Med. 2012; https://doi.org/10.7326/ 0003-4819-157-1-201207030-00450.

48. Ammenwerth E, Buchauer A, Bludau B, Haux R. Mobile information and communication tools in the hospital. Int J Med Inform. 2000;57:21-40.

49. Haun JN, Lind JD, Shimada SL, Martin TL, Gosline RM, Antinori N, Stewart M, Simon SR. Evaluating user experiences of the secure messaging tool on the veterans affairs' patient portal system. J Med Internet Res. 2014;16

50. Birkhead GS, Klompas M, Shah NR. Uses of electronic health records for public health surveillance to advance public health. Annu Rev Public Health. 2015;36:345-59.

51. Fox Bl, Pedersen CA, Gumpper KF. ASHP national survey on informatics: assessment of the adoption and use of pharmacy informatics in U.S hospitals-2013. Am J Health Syst Pharm. 2015;72:636-55.

52. Fernandez-Aleman $J L$, Senor IC, Lozoya PA, Toval A. Security and privacy in electronic health records: a systematic literature review. J Biomed Inform. 2013;46:541-62.

53. Papoutsi C, Reed JE, Marston C, Lewis R, Majeed A, Bell D. Patient and public views about the security and privacy of electronic health records (EHRs) in the UK: results from a mixed methods study. BMC Medical Informatics and Decision Making. 2015; https://doi.org/10.1186/s12911-015-0202-2.

54. TurkeyMoH. Standards of accreditation in health, hospital kit - v1.1/2015. Ankara: Pozitif Printing Press Ltd. Co.; 2015.

55. MoH. Tibbi Laboratuvarlar Yönetmeligi, vol. 28790: Resmi Gazete; 2013.

56. MoH. Hastane Bilgi Yönetim Sistemleri Alim Kilavuzu. In: IVMID B, editor. 5.1 ; 2010.

57. Esatoğlu AE, Köksal A. Hastanelerde Bilgisayar Teknolojisinin Kullanımı. Ankara Üniversitesi. Tıp Fakültesi Mecmuası. 2002;55:29-40.

58. Reid JH. Patient safety: staff safety - hand in hand? Journal of Perioperative Practice 2011;21:363.

59. Hughes RG, Blegen MA. Medication administration safety. In: Hughes RG, editor. Patient safety and quality: an evidence-based handbook for nurses. Rockville (MD); 2008

60. IOM. Preventing medication errors. Washington, DC: National Academy Press; 2007.

61. Backman C, Vanderloo S, Momtahan K, d'Entremont B, Freeman L, Kachuik L, Rossy D, Mille T, Mojaverian N, Lemire-Rodger G, et al. Implementation of an electronic data collection tool to monitor nursing-sensitive indicators in a large academic health sciences Centre. Nurs Leadersh. 2015;28:77-91.

62. Silow-Carroll S, Edwards JN, Rodin D. Using electronic health records to improve quality and efficiency: the experiences of leading hospitals.: the Commonwealth Fund; 2012.

63. TurkeyMoH. Transformation in health. 2003.

64. TurkeyMoH. Institutional performance and quality applications in healthcare. Ankara: Lazer Ofset; 2009.

65. Gualano MR, Bert F, Andriolo V, Grosso M, Minniti D, Siliquini R. Use of telemedicine in the European penitentiaries: current scenario and best practices. Eur J Pub Health. 2016; https://doi.org/10.1093/eurpub/ckw145.

66. Mehrotra A, Jena AB, Busch AB, Souza J, Uscher-Pines $L$, Landon BE. Utilization of telemedicine among rural Medicare beneficiaries. JAMA. 2016; https://doi.org/10.1001/jama.2016.2186.

67. Zhang XY, Zhang P. Telemedicine in clinical setting. Experimental and therapeutic medicine. 2016; https://doi.org/10.3892/etm.2016.3656.

68. Douglas MD, Xu J, Heggs A, Wrenn G, Mack DH, Rust G. Assessing telemedicine utilization by using Medicaid claims data. Psychiatr Serv. 2016; https://doi.org/10.1176/appi.ps.201500518.

69. Te Boveldt N, Vernooij-Dassen M, Leppink I, Samwel H, Vissers K, Engels Y. Patient empowerment in cancer pain management: an integrative literature review. Psycho-Oncology. 2014; https://doi.org/10.1002/pon.3573.

70. Jotterand F, Amodio A, Elger BS. Patient education as empowerment and self-rebiasing. Medicine, health care, and philosophy; 2016. https://doi.org/10.1007/s11019-016-9702-9.

71. King J, Patel V, Jamoom EW, Furukawa MF. Clinical benefits of electronic health record use: national findings. Health Serv Res. 2014;49:392-404.

72. Petrides AK, Bixho I, Goonan EM, Bates DW, Shaykevich S, Lipsitz SR, Landman AB, Tanasijevic MJ, Melanson SE. The benefits and challenges of 
an interfaced electronic health record and laboratory information system: effects on laboratory processes. Arch Pathol Lab Med. 2017;141:410-7.

73. Kruse CS, DeShazo J, Kim F, Fulton L. Factors associated with adoption of health information technology: a conceptual model based on a systematic review. JMIR Med Inform. 2014;2

74. Berner ES. Clinical decision support systems: state of the art. AHRQ publication. 2009;90069

75. Garg AX, Adhikari NJ, McDonald $H$, et al. Effects of computerized clinical decision support systems on practitioner performance and patient outcomes: a systematic review. JAMA. 2005; https://doi.org/10.1001/jama. 293.10.1223.

76. Levick DL, Stern G, Meyerhoefer CD, Levick A, Pucklavage D. Reducing unnecessary testing in a CPOE system through implementation of a targeted CDS intervention. BMC Med Inform Decis Mak. 2013;13:1472-6947.

Submit your next manuscript to BioMed Central and we will help you at every step:

- We accept pre-submission inquiries

- Our selector tool helps you to find the most relevant journal

- We provide round the clock customer support

- Convenient online submission

- Thorough peer review

- Inclusion in PubMed and all major indexing services

- Maximum visibility for your research

Submit your manuscript at www.biomedcentral.com/submit
Biomed Central 